\title{
WIND PROPULSION OPTIONS FOR ENERGY SHIPS
}

\author{
Gaël Clodic \\ LHEEA lab, Ecole Centrale \\ Nantes, France
}

\author{
Aurélien Babarit \\ LHEEA lab, Ecole Centrale \\ Nantes, France
}

\author{
Jean-Christophe Gilloteaux \\ LHEEA lab, Ecole Centrale \\ Nantes, France
}

\begin{abstract}
A new concept has emerged for far offshore wind energy conversion. It is the wind energy ship (1). It consists of a ship propelled by wind sails towing a water turbine. The water turbine produces electricity. The electricity is converted into a fuel (hydrogen for example). When the tanks are full, the ship sails to a terminal where the fuel is unloaded. Then, it can start a new charging cycle.
\end{abstract}

An energy ship consists in several sub-systems: wind propulsion subsystem, hull, water turbine, energy storage. The focus of this paper is on the wind propulsion subsystem because of the many options available. Indeed, it has been proposed to implement rigid sails $(2,3)$, kite wings $(4,5)$, airfoils $(1,7)$ or Flettner rotors (6).

Applying systems engineering, key requirements for the wind propulsion have been identified for the energy ship application. They are presented in the paper. Next, the advantages and drawbacks of each technology are discussed and most promising options are highlighted.

\section{INTRODUCTION}

Floating wind turbines have been developed $(8,9)$. They address the challenge of deeper water. The world's first floating wind farm is expected to start producing by the end of 2017 (10). The offshore wind technical potential available near shore $(<90 \mathrm{~km})$ and in intermediate water depth $(<200 \mathrm{~m})$ is in order of $180,000 \mathrm{TWh} / \mathrm{y}$ according to (11), which is less than the forecasted energy demand in 2050 in the reference scenario of (12) $(240,000 \mathrm{TWh} / \mathrm{y})$. To further increase the technical potential, wind energy conversion technologies which can be deployed far offshore (hundreds to thousands of $\mathrm{km}$ from shore) must be developed. There, it is no longer feasible from an economic perspective to use grid-connected wind turbines because grid-connection increases linearly with increasing distance to shore (13). Other means to transfer the energy from the source of production to the consumer must be considered. It involves energy storage for which many options (compressed air energy storage, batteries, hydrogen, etc.) are available (14).

A remarkable benefit of on-board energy storage for far offshore wind energy converters is that the constraint for the supporting platform to be stationary is removed. Being mobile has two advantages. Firstly, it removes the need for moorings \& anchors which has a significant impact on capital expenditures (CAPEX). According to (9), moorings and anchors (including installation) account for approximately $20 \%$ of CAPEX of typical floating offshore wind projects. Secondly, the system being mobile, it may sail to the resource which may lead to greater capacity factors. Note that capacity factor for offshore wind turbines is already rather high, being in average approximately $40 \%$ according to (9). Still, for harvesting the far offshore wind energy resource, it appears that mobile wind energy conversion systems may represent a cost competitive alternative to floating offshore wind turbines.

The energy ship is one of the concepts suggested for the far offshore wind harvesting (15). In energy ships, wind energy is primarily used to propel the ship. Then, electricity generation is obtained through a water turbine attached to the hull of the ship. A techno-economic feasibility of the energy ship concept has been conducted (15) and stated, for the hydrogen storage solution, the final hydrogen price that must be achieved to be competitive in the actual and future hydrogen market. From the assumptions taken in the study, there were great uncertainties on the on-board hydrogen production cost due to the lack of information on the ship design and performances. Work is in progress on the design optimization of such vessel to validate a 


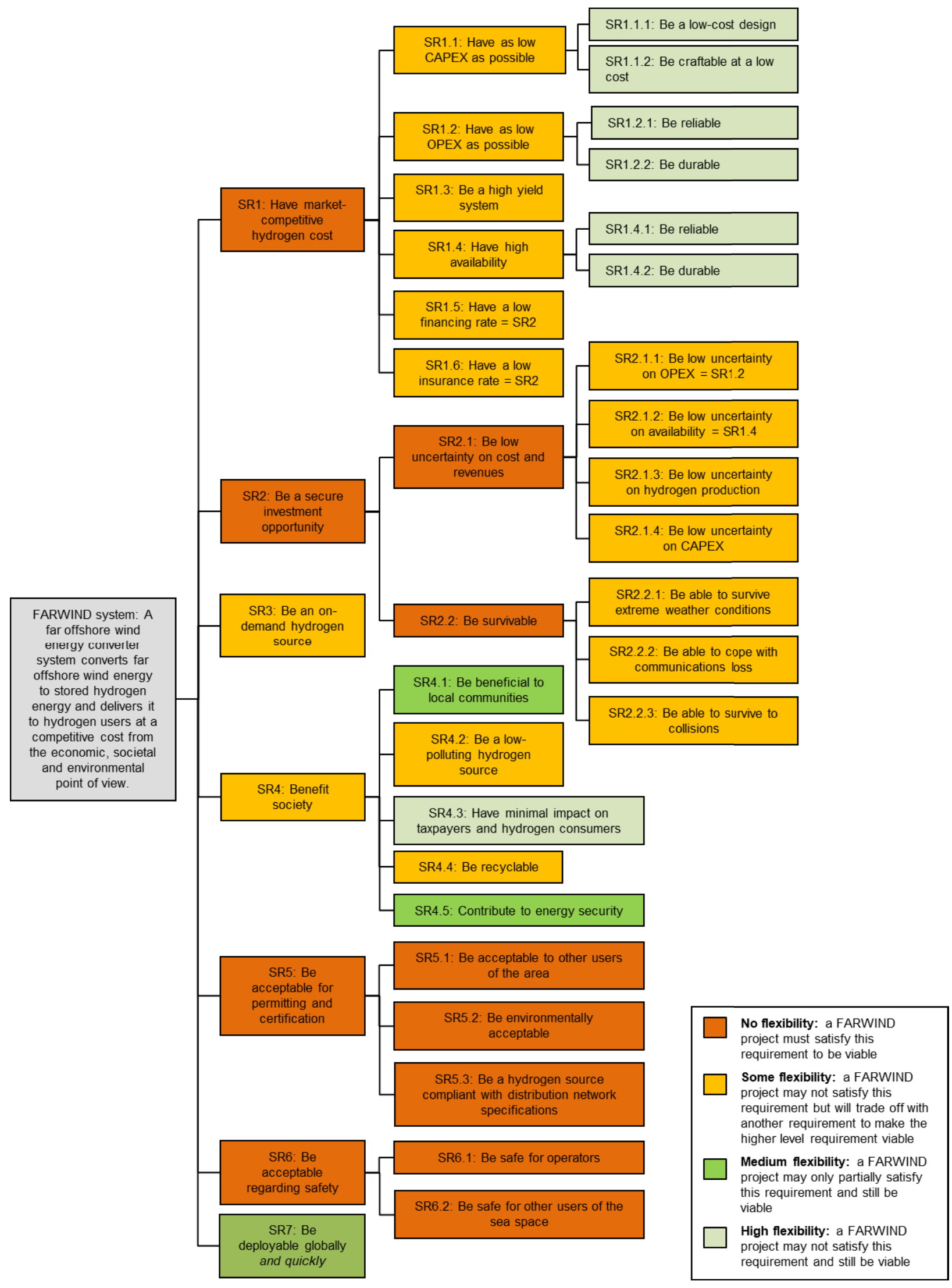

Figure 1. Stakeholders' requirements graph of a FARWIND project. 
more precise hydrogen production cost. To reach this objective, one step is to validate the technology choices of each subsystem composing the ship.

From the recent developments, technologies that suit to wind propulsion of freight ships have emerged. Flettner rotors (16), Turbo-sails (17), rigid or wing sails (18) and kite wings (19) have been recently developed and seem to be suitable. In this paper, we propose to draw advantages and drawbacks of each of these technologies for an application on energy ships.

\section{IDENTIFICATION OF REQUIREMENTS AND PERFORMANCES MEASURES}

\section{Stakeholder requirements}

Systems engineering techniques have been applied to a hydrogen energy ship project to identify and specify stakeholders' requirements for a commercially successful project. Following the systems engineering method used in "stakeholder requirements for commercially successful wave energy converter farms" (15), we first identified the mission of a FARWIND project: "A far offshore wind energy converter system converts far offshore wind energy to stored hydrogen energy and delivers it to hydrogen users at a competitive cost from the economic, societal and environmental point of view". We then proceed to identify and analyze all lifecycle stages from engineering and procurement to disposal. Then the list of all stakeholders interacting with the project at each lifecycle stages has been established. Finally we proceed to identify 28 stakeholders' requirements as shown on "Fig. 1.". Although some new requirements appeared (e.g. "SR2.1.2: Be able to cope with communication loss" or "SR3: Be an on-demand hydrogen source") and some others were non relevant to the far offshore wind energy project (e.g. "SR3: Be reliable for grid operations") the requirements for the FARWIND project are very similar from those of a Wave Energy Converter farm.

\section{Subsystems functions}

For completing the mission, function and sub-functions has to be completed. They are detailed on "Fig. 2.". Three systems associated to a specific function are distinguished: the terminal and distribution network (including soft distribution network) which "deliver hydrogen to end users, the tanker which "transport hydrogen from the converter to terminal" and the converter i.e. the energy ship which "produce hydrogen from wind energy". The wind propulsion system is associated to the energy ship's sub-function "convert wind energy to kinetic energy of marine platform".

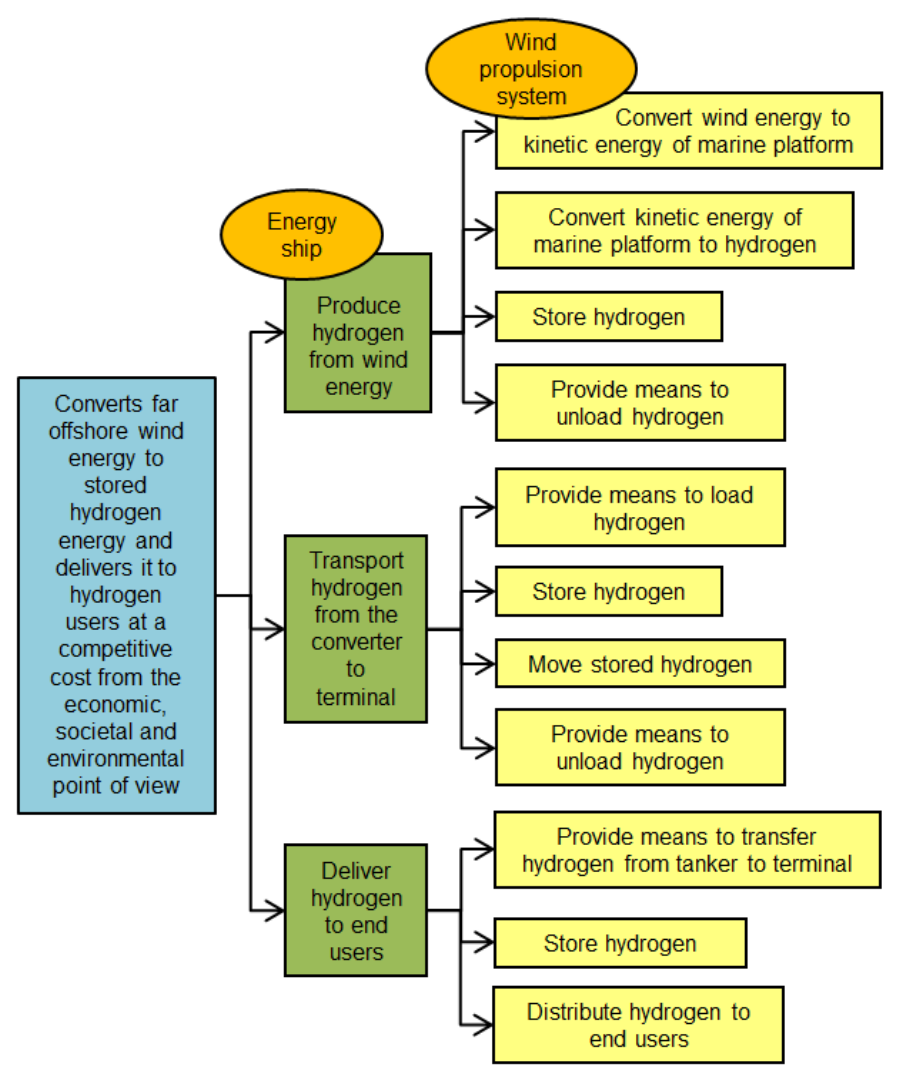

Figure 2. Function graph of a FARWIND project.

\section{EVALUATION OF WIND PROPULSION TECHNOLOGIES}

\section{Evaluation method}

To evaluate each wind propulsion technology we stated if they are able to make the FARWIND project fulfill the stakeholder's requirements. Each technology has been rated from 0 (worst rate) to 10 (best rate) for each stakeholders requirement. Each rate represents the qualitative evaluation of a technology to fulfill the studied stakeholders' requirement. To rate the technologies, we based our studies on performances metrics that represents all the parameters that could influence technologies' capacity to fulfill the stakeholders' requirements. The list of the performance metrics studied is shown on "Fig. 3.". Some of the stakeholders' requirements do not concern the wind propulsion system and then have not been rated (e.g. S.R.3: be an on-demand hydrogen source).

In the rest of this paper, we present the rates of four wind propulsion technologies: Flettner rotors, turbo-sails, rigid sails and kite wings. Important performances metrics are highlighted to explain stakeholders' requirements' rating. 


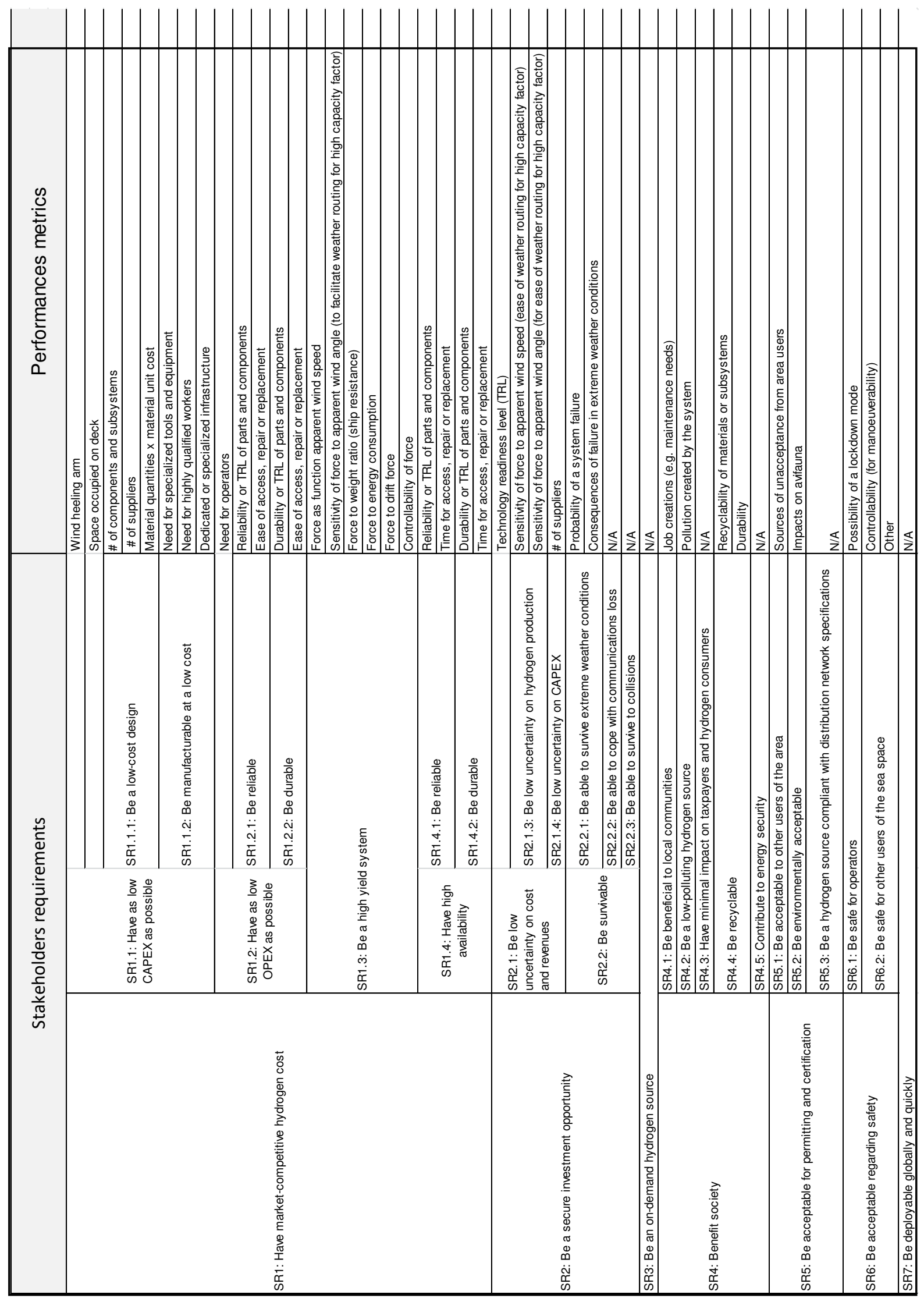

Figure 3. Performances metrics of the wind propulsion system associated to the stakeholders requirements of a FARWIND project. 


\section{Flettner rotors}

The Flettner rotor is a remarkable technology due to its excellent aerodynamics performances $(20,21,22,23)$. Indeed, such system is able to achieve a lift ratio up to 9 with a lift to drag ratio of 4 (21). The relatively low lift to drag ratio compared to the other technologies and the difficulty to adjust the aerodynamic force direction because of the circular symmetry of the profile make it more sensible to wind direction. This tends to make weather routing more difficult (low performances for some wind directions) and reduce the energy ship capacity to be a high yield system.

Flettner rotors are easy to automatize with only the rotation speed of the rotor to control.

The main drawback of Flettner rotor is the energy consumption of the rotor. The power consumption is about $80 \mathrm{~kW}$ for a rotor of $5 \mathrm{~m}$ diameter and $30 \mathrm{~m}$ high (24) and is equivalent to $10 \%$ of the propulsive power produced for a ship sailing at $15 \mathrm{kts}$. This aspect tends to slightly decrease the aerodynamic performances.

With a wind speed equivalent to BF10 (i.e. $55 \mathrm{kts}$ ) the force exerted by the wind on a non-rotating rotor is fewer than the nominal conditions of the same Flettner rotor (i.e. rotating rotor with a wind speed of 20kts). This consideration, reinforced by the simplicity of the architecture of the system, contributes to minimize development and constructions costs. It also reinforces the survivability of the system.

There are few uncertainties on costs and revenues because Flettner rotor is a well-developed technology. Indeed, thanks to the recent developments, it achieves a technologic readiness level of 9 with two fully operational vessels equipped with this propulsion technology $(24,25)$.

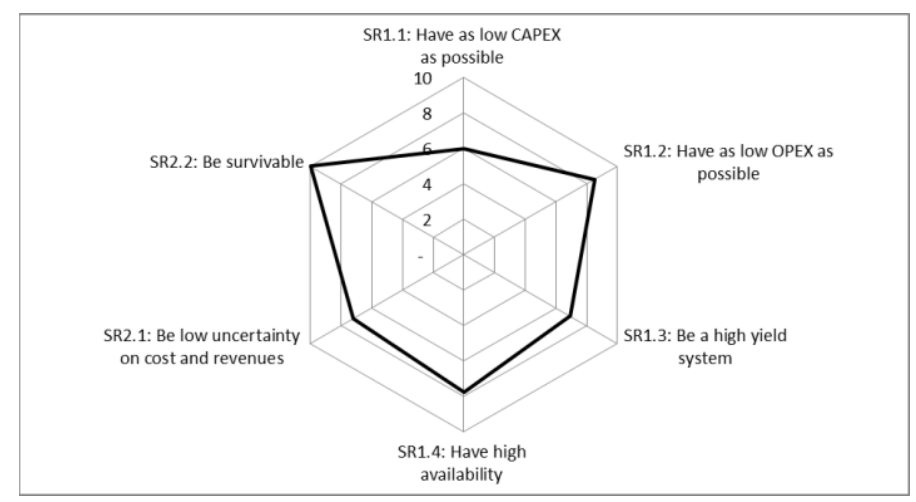

Figure 4. Flettner rotor results.

Turbo-sails

Turbo-sails are very similar to Flettner rotor both from aerodynamic, architecture and operation point of view. It has a fewer but quite high lift ratio of about $5.4(26,27)$ completed with a good lift to drag ratio of $7.8(26,27)$. The power consumption needed is supposed to be $7.5 \%$ of the propulsive power for a ship sailing at $15 \mathrm{kts}(28)$, which is fewer than the power consumption of a Flettner rotor.

The system consisting of several moving parts (e.g. mobile flap, adjustable suction area, air turbine...) can be sensitive to the hostility of at sea environment. The turbo-sail also have a larger sail area. These two factors decrease its survivability.

Turbo-sail technology has achieved a final development maturity thanks to the work of Fondation Cousteau (17) and the operation of the Alcyone (ref), a fully functional Turbo-sail equipped vessel. Nevertheless there was no recent proof of development or project based on the turbo-sail system and an update is needed to access to more precise and up to date characteristics.

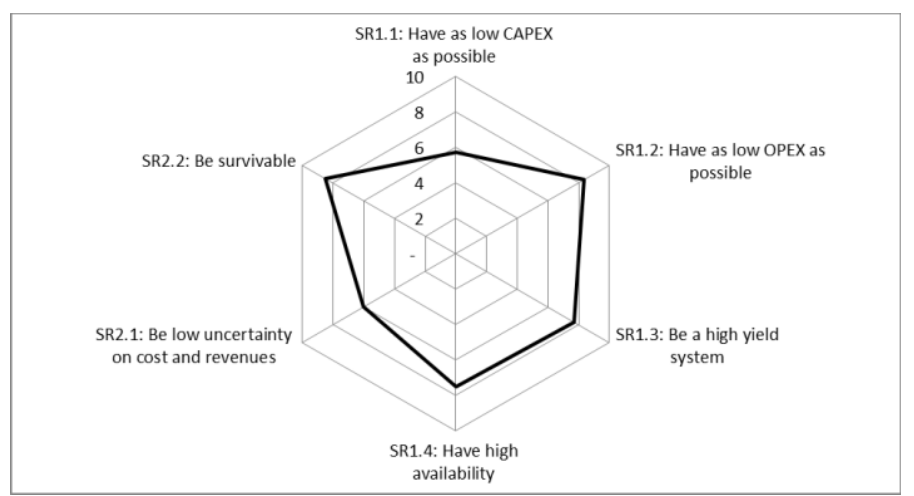

Figure 5. Turbo-sails results.

Rigid sails

Rigid sails are the recent high efficient sails. Due to the differences in profiles' shapes and sizes it is hazardous to describe them with a unique lift or drag ratio. We can still state that rigid sails are characterized by a good lift ratio (generally between 1 and 3 (29) plus an excellent lift to drag ratio (up to 50) that enable the ship equipped to sail with good efficiency in any wind direction including upwind.

Rigid sails are a mature technology with lots of studies and equipped vessel $(18,29,30)$ that leads to low uncertainties on costs. The simple architecture with no huge motor participates to both reducing the cost and increasing the performances.

In terms of survivability, rigid sails suffer from their large sail area and good aerodynamic performances. A retractable system is required to ensure the survivability of the sail and the ship. Options are available to retract the sail (18). The need of such system is a drawback for safety (a failure to retract the sail can have dangerous consequences) and may induce regular planned maintenance to maintain system's reliability. 


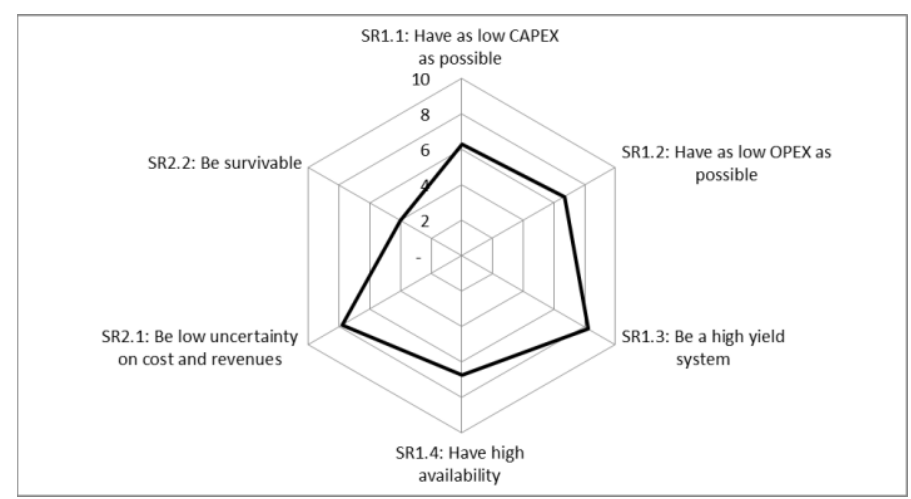

Figure 6. Rigid sails results.

Kite wing

Kite wing could have very high aerodynamics performances $(31,32)$. Thanks to altitude of the wing, it is able to reach higher wind speed and therefore increase the propulsive force with a low sail area (33).

This technology has a relatively low TRL and uncertainties remain about the performances and reliability of a completely automated kite wing. The technology is thus not yet ready to operate on an energy ship, but thanks to the actual developments (31), we expect a higher TRL level of this technology in the next years.

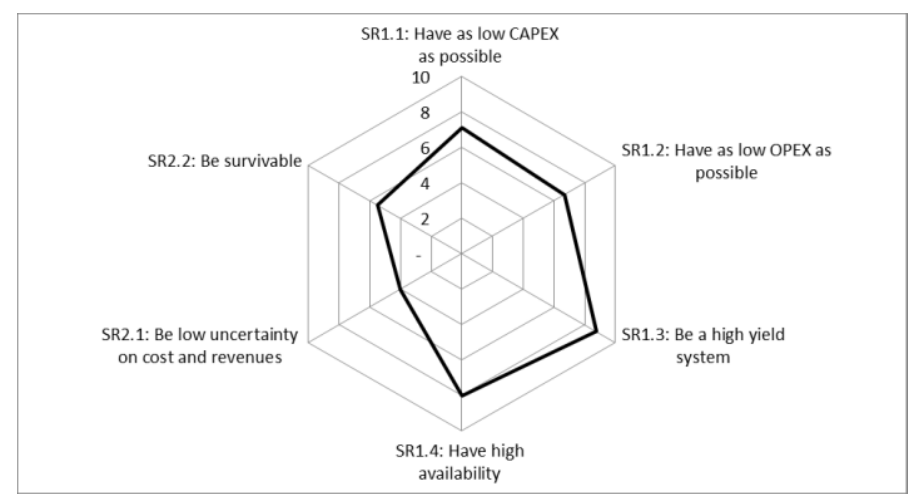

Figure 7. Kite wings results.

\section{DISCUSSIONS AND CONCLUSION}

Applying systems engineering, key requirements for a successful AFRWIND project has been identified (see "Fig. 1."). The FARWIND project has been decomposed in systems and sub-systems associated to specific functions (see "Fig. 2."). The system "energy ship" aim to "produce hydrogen from wind energy". The propulsion subsystem of the energy ship is a key subsystem for its performances. We discussed advantages and drawbacks of each technology and most promising options have been highlighted.
To evaluate wind propulsion technologies' ability to make the FARWIND project successful we evaluate the influence of each technology on the stakeholders' requirements. To evaluate this influence we relied on performances metrics that summarize the parameters and specifications that could influence stakeholders' requirements (see "Fig. 3.").

All the technologies selected (Flettner rotors, Turbo-sails, rigid sails and kite wings) have very good aerodynamic performances and are able to fulfill the energy ship's function "convert wind energy into kinetic energy of the marine platform".

Flettner rotors and Turbo-sails are the most polyvalent technologies regarding the stakeholders' requirements. They don't suffer of major weakness for an application on an energy ship. The Flettner rotor technology has already been proved many times on cargo sized vessels and is ready to use. Although Turbo-sail technology has achieved in 1985 a full technologic maturity, it lacks of recent proof of development and of examples of use on cargo sized vessels.

Rigid sails technology is also very promising for an application on an energy ship. It is a very well developed technology with good aerodynamic performances. It has better upwind performances than Flettner rotors and turbo-sails. While Flettner rotors and Turbo-sails don't need specific operation or system to survive extreme weather conditions, rigid sails must be retractable.

Kite wings could have very high aerodynamics performances and can be adapted on an energy ship but the technology is less mature than other wind propulsion technologies. More results and examples of applications on cargo sized vessels are required to state on the ability of kite wings to fulfill FARWIND project stakeholders' requirements.

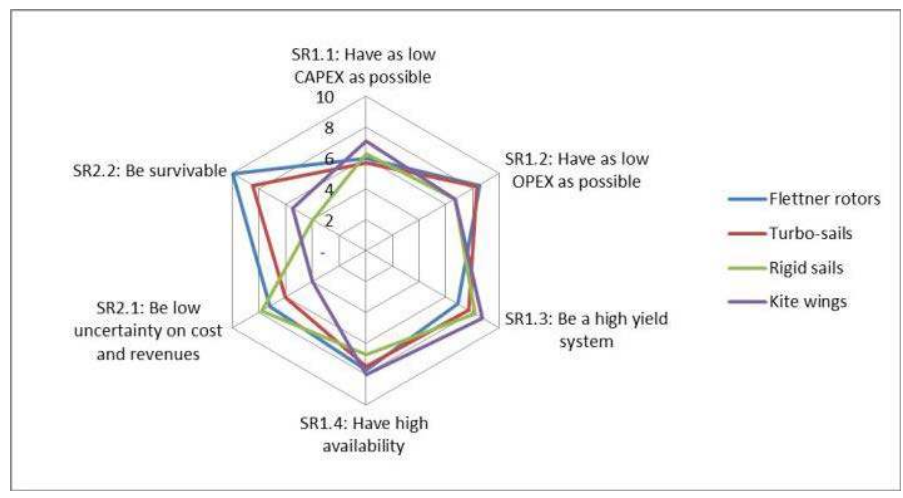

Figure 8. Flettner rotors, turbo-sails, rigid sails and kite wings results. 


\section{REFERENCES}

(1) Platzer M.F., Sarigul-Klijn N., Young J., Ashraf M.A., Lai J.C.S. (2014) Renewable hydrogen production using sailing ships. ASME Journal of Energy Resources Technology, Vol. 136

(2) Salomon R.E. (1982) Process of converting wind hydrogen to elemental hydrogen and apparatus therefor. U.S. Patent 4335093 A

(3) Gizara A.R. (2007) Turbine-integrated hydrofoil. U.S. Patent 2007/0046028A1

(4) Kim J., Park C. (2010) Wind power generation with a parawing on ships, a proposal. Energy, Vol. 35, pp. 1425-1432

(5) http://www.energy-observer.org/

(6) Gilloteaux J.C., Babarit A. (2017) Preliminary design of a wind driven vessel dedicated to hydrogen production. In Proc. of the ASME 36th International Conference on Ocean, Offshore and Artic Engineering (OMAE2017), Trondheim, Norway.

(7) K. Ouchi, J. Henzie (2017) Hydrogen generation sailing ship: conceptual design and feasibility study. In Proc. of IEEE OCEANS 2017

(8) Roddier D, Peiffer A, Aubault A, Cermelli C. (2017) Summary and conclusions of the full life-cycle of Windfloat FOWT prototype project. In: Proc. of the 36th international conference on ocean, offshore and artic engineering, Trondheim, Norway;

(9) James R, Costa Ros M. (2017) Floating offshore wind: market and technology review. Carbon trust. 2015. June 2015

(10) http://www.bbc.com/news/business-40699979 accessed on July, 27,.

(11) Lu X, McElroy MB, Kiviluoma J. (2009) Global potential for windgenerated electricity. Proc Natl Acad Sci Unit States Am

(12) A. Kitous, K. Keramidas, T. Vandysck. B. Saveyn (2016) GECO 2016. Global energy and climate outlook. road from Paris. EUR 27952 EN.

(13) Offshore wind programme board. Transmission costs for offshore wind. Final report, April 2016. Downloaded from https://ore.catapult.org.uk/wp-content/uploads/2016/05/

Transmission-Costs-for-Offshore-Wind.pdf.

(14) Chen H, Ngoc Cong T, Yang W, Tan C, Li Y, Ding Y. Progress in electrical energy storage system: a critical review. Prog Nat Sci 2009; Vol. 19, pp. 291-312.

(15) Babarit A., Gilloteaux J.C., Clodic G., Duchet M., Simoneau A., Platzer M. F. (2018) Techno-economic feasibility of fleets of far offshore hydrogen-producing wind energy converters, Int. J. of hydrogen energy, Vol. 43 Issue 15, pp. 7266-89.

(16) Talluri L., Nalianda D.K., Giuliani E. (2018) Techno economic and environmental assessment of Flettner rotors for marine propulsion, Ocean Engineering, Vol. 154, pp. 1-15.

(17) Charrier B., Constans J., Cousteau J.Y., Daïf A., Malavard L., Quinio J.L. (1985) Fondation Cousteau and windship propulsion, Journal of wind Engineering and industrial aerodynamics, Vol.20 pp. 39-60.

(18) Ouchi K., Uzawa K., Kanai A., Katori M. (2013) "Wind Challenger" the Next Generation Hybrid Sailing Vessel, $3^{\text {rd }}$ Internationnal Symposium on marine propulsors, Launceston, Autralia.

(19) Fritz F. (2013) Application of an Automated Kite System for Ship Propulsion and Power Generation, Airborne energy, pp. 359-72.

(20) Badalamenti C., Prince S.A. (2008) The Effects of Endplates on a Rotating Cylinder in Crossflow, 26th AIAA Applied Aerodynamics Conference, Honolulu, Hawaii.

(21) Thouault N., Breitsamter C., Seifert J., Badalamenti C., Prince S.A., Adams N.A. (2010) Numerical analysis of a rotating cylinder with spanwise discs, $27^{\text {th }}$ Internationnal congress of the aeronautical sciences.

(22) Pearson D.R. (2014) The sue of Flettner rotors in efficient ship design, Influence of EEDI on Ship Design, London, UK

(23) Talluri L., Nalianda D.K., Giuliani E. (2018) Techno economic and environmental assessment of Flettner rotors for marine propulsion, Ocean engineering, Vol. 154 pp. 1-15.

(24) Enercon presentation (2013) $4^{\text {th }}$ conference on ship efficiency, Hamburg, Germany.

(25) Craft T., Jhonson N., Launder B. (2014) Back to the Future? A Re-examination of the Aerodynamics of FlettnerThom Rotors for Maritime Propulsion, Flow Turbulence Combust, Vol. 92, pp. 413-27.

(26) Low H.T., Luo S.C., Winoto S.H. (1991) Flow past a wind-assisted ship propulsion device, Ocean engineering, Vol. 18 , pp. 555-65.

(27) Hcini C., Abidi E., Kamoun B., Afungchui D. (2016) Numerical prediction for the aerodynamic performance of Turbosail type wind turbine using a vortex model, Energy, Vol. 109, pp. 287-93.

(28) Cousteau J.Y, Malavard L.C., Charrier B. (1981) Demande de brevet européen $\mathrm{n}^{\circ} 0055638$.

(29) Lee H., Jo Y., Lee D.J., Choi S. (2016) Surrogate model based design optimization of multiple wing sails considering flow interaction effect, Ocean Engineering, Vol. 121, pp. 422-436.

(30) Fujiwara T., Hearn G.E., Kitamura A., Ueno M. (2005) Sail-sail and sail-hull interaction effects of hybrid-sail assisted bulk carrier, Journal of marine science and technology, Vol. 10 pp. 82-95.

(31) Leloup R., Roncin K., Bles G., Leroux J.B., Jochum C., Parlier Y. (2014) Kite and classical rig sailing performance comparison on a one design keel boat, Ocean engineering, vol. 90, pp.39-48.

(32) Traut M., Gilbert P., Walsh C., Bows A., Filippone A., Stansby P. Wood R. (2014) Propulsive power contribution of a kite and a Flettner rotor on selected shipping routes, Applied energy, Vol. 113, pp. 362-72.

(33) Kim J., Park C. (2010) Wind power generation with a parawing on ships, a proposal, Energy, Vol. 35, pp. 1425-32. 